\title{
A Critical Review of Grammar Teaching Methodologies in the Saudi Context
}

\author{
Abeer Sultan Althaqafi ${ }^{1}$ \\ ${ }^{1}$ English Language Institute (ELI), King Abdulaziz University (KAU), Jeddah, Kingdom of Saudi Arabia \\ Correspondence: Abeer Sultan Althaqafi, English Language Institute (ELI), King Abdulaziz University (KAU), \\ Jeddah, Kingdom of Saudi Arabia. E-mail: abalthagafi@kau.edu.sa
}

Received: September 11, 2018

Accepted: October 8, 2018 Online Published: October 10, 2018

doi: 10.5539/elt.v11n11p65

URL: http://doi.org/10.5539/elt.v11n11p65

\begin{abstract}
'Grammar is the business of taking a language to pieces, to see how it works' (Crystal, 1996, p. 6). The study of grammar has fascinated people for many years, especially in the field of second language acquisition (SLA). However, in recent years people became uncertain about its value. Consequently, some educational institutions ceased to teach it, others teach it very selectively (Crystal, 1996; Ellis, 2002). To know grammar means to know more about how to manipulate the parts of a sentence in order to provide a meaningful expression. Teaching grammar has been subjected to a tremendous change, particularly throughout the twentieth century. There has always been a development in thinking about the nature of language which has enabled people to see the point of the study and teaching of grammar. Also, there have been quite a number of adaptations of various methodologies of teaching grammar. This language component (grammar) has been always the centre of pedagogical attention. The aim of this project is to discuss the changing role of teaching grammar from a Saudi teacher's perspective, and to explore why some Saudi EFL teachers might wish to change their approach to teaching grammar and how they might do so. In addition, the following section will try to shed light on some of the salient grammar methods throughout the field of English language teaching (ELT) and provide some implications for EFL teachers and learners.
\end{abstract}

Keywords: grammar teaching, teaching methodologies, task-based learning, and communicative language teaching

\section{Introduction}

First of all, it is essential to establish the fact that grammar can carry different interpretations and insights. As a consequence, each practitioner has their own view point. This may mean simply teaching to a grammar syllabus without any references to grammar inside classrooms. Conversely, it may mean teaching to a communicative syllabus by doing communicative activities. According to Lindsay and Knight (2006, p. 10):

'Grammar is the most important element of learning a language' is an example of a learning theory that directly affects learners. Expert opinions on how important grammar teaching is for learning language change regularly. It also depends on learner types. For young children grammar teaching is likely to be less useful than giving them practical experience and helping them develop vocabulary. But for older learners, knowledge of how the language works in terms of sentence building, word endings, and the relationship between words is essential for them to be able to express themselves.

In fact, grammar has undergone many eras of methodological trends, some teaching methods come, some others go, but they come around again -this cyclical process is ongoing- (Thornbury, 1999). However, it may be useful if we summarise some of the most salient grammar teaching methods before drawing some conclusions from recent research, as presented in the following table.

Table 1. Salient teaching methodologies

\begin{tabular}{lll}
\hline Teaching Methodology & Year & Salient Features \\
\hline Grammar-Translation & $17^{\text {th }}-18^{\text {th }}-$ early $20^{\text {th }}$ & $\begin{array}{l}\text { - Took grammar as the starting point for instruction } \\
\text { followed by a translation exercise to and from the }\end{array}$ \\
(The Classical Method) & Centuries & \begin{tabular}{l} 
S \\
\hline
\end{tabular}
\end{tabular}




\section{Direct Method}

(Natural Method)

Audiolingualism

(Army Method)

Communicative Language
Teaching
(CLT)/Communicative
Approach

Task-Based Learning (TBL)/ or Task-Based Instruction (TBI)

Approach
Gouin and Berlitz

(1880)

1950s

North American invention after the outbreak of World War II

\section{0s}

The outcome of the developments in the science of sociolinguistics based on (Prabhu's project Bangalore)

Was popularized by Prabhu while working Bangalore

in mother tongue.

- focused on the written language.

- Accuracy is emphasized.

- Grammar is taught deductively.

- Prioritised oral skills, rejected explicit grammar teaching.

- Learners supposed to pick up grammar by being immersed in language.

- Stayed faithful to the Direct Method belief in the primacy of speech.

- considered language as a form of behaviour, to be learned through the formation of correct habits.

- Its strong alliance is the American Structural Linguistics and its applied linguistic applications, particularly contrastive analysis.

- Grammatical knowledge is a component of communicative competence.

- Rejected grammar-based syllabuses and grammar instruction to move towards a more communicative practice.

- Focused on the use of authentic language and requires students to do meaningful tasks using the target language.

- The assessment is primarily based on the appropriate completion of tasks.

It appears from the above table that there have been different emphases with regard to the way the learner could deduce grammatical rules. In Grammar-Translation, the rules are simply presented to the learner in a deductive approach (rule-driven) path. On the other hand, other approaches such as CLT and Task-Based Instruction often require the learners first to study examples and then try to extrapolate the rules by themselves as in an inductive approach (rule-discovery) path. Furthermore, it should be mentioned that there were other methodologies such as: Silent way (characterised by a problem-solving approach), and Suggestopedia (characterised by the use of music and relaxation as a means of retaining new knowledge and material) which were demolished on several fronts. For example, Brown (2000) stated that in Silent way, the teacher was distant and the classroom environment was not conductive to learning. On the other hand, Suggestopedia can be practiced from time to time since a relaxed mind is an open mind, but what would happen if the classroom are bereft of CD players or any other devices. Moreover, it can be noted that all these methods except for the Grammar-Translation tended to place more weight on being intelligible than on being correct. So, they tended to present fluency-to-accuracy. This entails huge debate that needs more time and space, however, let us focus on one context to elaborate and understand arguments more. The next section will endeavour to explore the grammar debate in terms of its current application in Saudi Arabia from a Saudi perspective.

\section{The Changing Methodologies of Teaching Grammar: An Extract from a Saudi Context}

Based on my research as a Saudi teacher and a former student in a number of Saudi Schools, it can be assumed that teaching grammar has undergone different changes since 1927, when teaching English language as a foreign language was first introduced. Between 1927 and 1970s, there was a former belief assuming that a student's mind was an empty vessel to be filled by books or lectures. Thus, students remained as silent as a receptacle waiting for knowledge and ideas to be poured into their minds. At that period of time, grammar was given a considerable amount of concern in language teaching more than any other components, it was regarded as the 
discipline of the mind. Therefore, the grammar lesson was actually the language lesson. Teachers were teaching structural grammar syllabus without making any reference to situational contexts at all. Textbooks involved statements of abstract grammar rules, lists of vocabulary followed by exercises involving translation into and out of the mother tongue (as was the case with Grammar-Translation Method). The title of the grammar lesson was stated explicitly on the front line of the lesson, this acted like an alert to what was going to come next (see appendix 1 for more explanations). Students were made to learn by memorizing each component of a sentence without pointing out what the task was intended to do. Moreover, oral application of the target language was not the goal, and oral practice was limited to pupils reading aloud the sentences they had translated. It seems that this way of overt grammar teaching focused on the structure of sentences at the expense of oral practice, and deprived students of the adequate exposure to the target language through listening and reading. At that time many were misled to believe that our students were learning the target language, however, it was revealed that such claims were untrue since the majority of the learners were not able to produce sufficient full correct sentences (Al-Qurashi, 1995).

However, during the mid-nineteenth century, there were some attempts to make second language learning more like first language acquisition with a focus on oral proficiency, therefore, Saudi educators stepped forward to adapt a more behaviouristic method of teaching, which is 'Audio-lingual Method' (Al-Mutawa and Kailani, 1989). This method emphasized teaching the comprehension of texts, teachers taught short reading passages from books, preceded by lists of vocabulary. Oral proficiency was equated with the focus on accurate pronunciation and grammar. It should be noted that dialogues and drills form the basis for such method. After presenting a dialogue, teacher can choose specific grammatical patterns in the dialogue and become the focus of various drills and exercises.

In analysing these standard models of the language lesson presentations from the beginning to mid-nineteenth century in most Saudi classrooms, it could be suggested that they are presentation and practice.

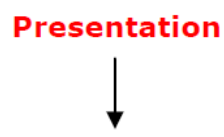

Practice

The aim of such a model was to teach a specific language form or to present a particular function or notion. It shows from the above model that the focus was on achieving accuracy rather than fluency. However, later on educationalists recognised that accuracy alone is not enough to master a great deal of a second language, so a third element was added which is: production. This new method has come to be known as the PPP model.

\section{Presentation $\longrightarrow$ Practice $\longrightarrow$ Production}

According to Thornbury (1999), this kind of organisation is a typical feature of most English language course books. It has a systematic logic, therefore, it is easy to apply and measure against the time and effort involved. Nevertheless, it has been reported that this PPP cycle restricts the learner's experience of language by focusing on a single item (Willis, 1996).

By the late 1990s, grammar teaching had undergone many developments and applications in the world, so the Saudi Ministry of Education tried to react to the new insights by implementing them into the curriculum. This need to take advantage of the new methods and the views of educators outside and inside the country, resulted in the production of a new series of books. Although there was a new shift in the way of introducing grammar lessons inside classrooms, many new books still followed the same PPP model sequence of presenting grammar. Nevertheless, an alternative model evolved reversing the progression of the PPP Model upside down, giving the priority to fluency-to-accuracy since language is all about conveying message without the need for being precise about the single components of the language. In fact, the proponents of the communicative approach introduced this fluency model (Task-Based). It assumes that the learning chain begins with the meaning that is needed to be conveyed, then, receiving some guidance that may include explicit grammar instruction during the latter stages of the lesson (Swan, 1995; Willis, 2004) (Note 1). It is represented by providing students with taught material then practice, before learners re-perform the original or a similar task:

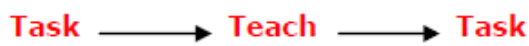


Willis (1996), who is a famous proponent of TBL, considers this model as a logical development of Communicative Language Teaching since it draws on several principles that formed part of this approach with an organized focus on the form. However, this Task-Based Model is not without its problems. For instance, it is debated what criteria determines the selection, ordering or the evaluation of the tasks. The following table will try to summarise some major differences between Task-Based Model and PPP:

Table 2. Task-Based Model vs. PPP Model

\begin{tabular}{ll}
\hline The PPP Model & The T-Based Model \\
\hline - Most applied activities seem completely & - Focuses on applying authentic materials and tasks. \\
unnatural. & - Accuracy develops from fluency. \\
- Fluency develops from accuracy. & - Language is taught in chunks and applied \\
- Language is taught in layers and fixed steps. & $\begin{array}{l}\text { leaps. } \\
\text { - The knowledge of grammar is a procedural }\end{array}$ \\
process that develops through practice. & - The knowledge of grammar develops through \\
\hline
\end{tabular}

The above table shows the disparagy between the PPP model and Task-based model. It should be noted that the latter one offers far more opportunities for free language use and the linguistic content of the language. To summarise the comparison, it can be said that task-based model begins by providing learners with a holistic experience of language and then helps them to analyse the structure of this language to help them learn more effectively. On the other hand, many can concur that PPP provides isolated discrete items of a language and then looks for some activities to practice (Willis, 1996).

Moreover, as a result of all the former studies in the grammar field, grammar was integrated in all English modules course books using more communicative methodologies of teaching. The most presentations of rules are conducted in an implicit way to engage students more within the process of learning. Nowadays, grammar is still given a proper place in Saudi classrooms, but is taught in an integrated way that it does not overshadow other elements of language teaching. Furthermore, it should be mentioned that this insight has led to some changes in the use of other principles such as metalanguage and providing feedback during grammar classes. The next paragraphs will try to summarise some of those important changes.

\subsection{The Use of Metalanguage}

The use of metalanguage in explaining grammar lessons is unavoidable in most Saudi classes both historically and currently. Almost all types of schools start teaching the mother language as well as foreign language(s) with the use of metalanguage from the age of ten. This is the only aspect of teaching grammar which has remained constant throughout the changes in the field of grammar teaching. Most Saudi educators believe that it is more advantageous to refer to metalanguage through explaining grammatical rules. Their thoughts are aligned with the beliefs of $\mathrm{Hu}$ (2002), which can be summarised as follows:

- It is more useful to refer to metalanguage when explaining complex structure or when using conscious raising activities.

- Knowing metalanguage helps learners to become autonomous and discover things for themselves.

- Metalanguage allows precision in explanations and delimitation of context.

- Metalanguage can help students to draw links between new and learnt structures.

\subsection{The Changing Role of Feedback}

In the past as in most Grammar-Translation classes, there was a direct method of approaching mistakes and correcting them immediately to stop the formation of bad habits and not to allow fossilised errors. Later on, researchers and educators showed concern about how we correct errors and what is our rationale? Many researchers found it demotivating for students to put them under the microscope and perpetually tackling all their individual mistakes. However, according to Ellis (2006) and Long (1996), providing learners with corrective feedback is important for learning grammar and it is best conducted by using a mixture of implicit and explicit feedback when the learner begins to use the language productively. In fact, most Saudi teachers nowadays are aware of the significant role of giving feedback and the implicit way it can be presented and they become more lenient when dealing with their students errors, since they are concerned about the bigger picture not the minor 
errors.

Furthermore, it should be mentioned that almost all the teachers in most Saudi schools and educational institutions are still obliged to teach a course book chosen by the Higher or General Ministries of Education. These textbooks are the core of curriculum in most of our classes. Consequently, most Saudi teachers do not have the absolute freedom to choose the course book needed to be taught or even the syllabuses. Many linguists such as: Swan (1995); Yule (1998); and Thornbury (1999) believe that although the criteria for selecting the items that feature in a syllabus are based on usefulness and frequency, it can be argued that these two criteria are dependent on the specific needs of the learner. However, it is believed that no one can better know the needs of learners more than the teacher. In fact, this demonstrates a lack of trust in teachers' professional judgement and puts them under the pressure covering materials that might not be of interest to students.

Moreover, it should be noted that research has shown that the current pre-service teacher-training program in Saudi Arabia is not completely efficient in replacing the tradition methodologies of language teaching (Al-Mutawa \& Kailani, 1989, Althaqafi, 2015). In addition, there are some challenges need to be considered by Saudi educationalists at the Ministry of Education, such as: time constraints, the availability of adequate learning aids, and over-crowded classrooms which lead to a constant pressure on the teachers. These challenges appear to be reflected in teachers' approaches to teaching the language.

Accordingly, it can clearly be noted from the above discussion that grammar teaching in Saudi classes is still the most controversial and least understood component of language teaching. However, Saudi teachers are recommended to be enlightened to the developments in second language acquisition research and practice to obtain new strategies that match the nature of the language as well as the nature of the learners.

In the next section, we will view some basic implications for grammar teaching and aspects that teachers should consider before starting any grammar class.

\section{Implications for Teaching and Teachers}

Many concur with the idea that the former grammar lesson was dry, boring, and lacking interactivity. It was claimed then that teaching students to analyse sentences would improve their spoken and written language. Nevertheless, there lacked any supporting evidence to prove the correctness of such claims (Crystal, 1996). Moreover, it should be noted that grammatical analysis in English is extremely complex. There are always exceptions to rules, therefore, it will be unfruitful to focus on rules only or separate them from meaning and context. Despite the quantity of trends of grammar teaching methods that have been referred to earlier, the reality is that very few teachers find themselves adhering to any single method in its entirety. Teachers do not want to take others' prescriptions and apply them simply into class because each practitioner has his/her own personal way of professionalism in the classroom (Scrivener, 2005). Some learners demand grammar, whilst others learn better by talk, therefore, it is of paramount importance for the teacher to respond effectively to these demands and provide a balance where possible in a climate with an array of methodological fashions.

Having this discussion enables us to outline the following points for the teacher to put into consideration in grammar teaching:

- The aim of teaching grammar is to facilitate the learners' comprehension and production of the language, rather than as an end in itself (Thornbury, 1999).

- Grammar is best taught to people who already have accumulated some ability towards the proper use of the language rather than to complete beginner or young children (Ellis, 2006).

- The type of the grammatical function of the language exponent tells the teacher what suitable method to apply.

- There are some pedagogical characteristics of each model can be combined in lessons which are skills- or text-based.

- In grammar teaching the grammatical forms should be taught in association with their meanings.

- Focusing on the form can be explicit or implicit, depending on the presented materials as in the case of story-telling.

- Grammatical knowledge is proceduralised through practice and develops through exposure and interaction (Thornbury, 1999).

\section{Conclusion}

Accordingly, it appears that grammar is a widely discussed area, and its history is the history of claims and counterclaims. These diverse claims and attitudes towards grammar and the way it should be presented underpin 
differences amongst methods, teachers and learners. Providing an example from a Saudi context shows us that there was overt grammar teaching applied inside most Saudi classrooms in the past, whilst the situation has reversed to be a more covert way of teaching, based mainly on communicative activities through interesting games and collaborative work using a mixture of implicit and explicit feedback. Although teaching grammar is communicatively oriented, it seems that the implementation of CLT is a serious challenge for Saudi teachers. Therefore, it is recommended for future research to further investigate the constraints that might hinder implementing this new communicative insight such as: the availability of adequate teaching and learning aids, the over-crowded classrooms and the role of assessment in overcoming flaws in EFL examination. However, the study of grammar has always been with us since the early days of the study of languages and will always be.

\section{References}

Al-Mutawa, N., \& Kailani, J. (1989). Methods of Teaching English to Arab Students. Harlow: Longman.

Al-Qurashi, K., Watson, M., Hafseth, J., Hickman, D., \& Pond, R. (1995). 'English for Saudi Arabia: First year Secondary, Teacher's book'. Riyadh: Ministry of Education Press.

Althaqafi, A. (2015). Perceptions of Pioneer Female Saudi Higher Education EFL Teachers: A Qualitative Study of their Experiences in English Language Teaching ( $\mathrm{PhD}$, unpublished).

Crystal, D. (1988). Rediscover Grammar. London: Longman.

Ellis, R. (2002). Grammar teaching- practice or consciousness-raising? In J. C. Richards, \& W. A. Renandya (Eds.), Methodology in Language Teaching: An Anthology of Current Practice (pp. 197-177). Cambridge: Cambridge University Press. https://doi.org/10.1017/CBO9780511667190.023

Ellis, R. (2006). Current issues in the teaching of grammar: An SLA perspective. TESOL Quarterly, 40(1), 83-107. https://doi.org/10.2307/40264512

Hewings, A., \& O'Halloran, K. (2004). Applying English Grammar: Functional and Corpus Approaches. The Open University Press.

Hu, G. (2002). Psychological constraints on the utility of metalinguistic knowledge in second language production. Studies in Second Language Acquisition, 24, 347-386. https://doi.org/10.1017/S02722631020 03017

Lindsay, C., \& Knight, P. (2006). Learning and Teaching English: A Course for Teachers. Oxford: Oxford University Press.

Long, M. H. (1996). The role of the linguistic environment in second language acquisition. In W. Ritchie, \& T. Bhatia (Eds.). Handbook of Second Language Acquisition (pp. 413-468). San Diego, CA: Academic Press.

Qualifications and Curriculum Authority, QCA (2004). An Introduction to the Grammar of Talk. .London: QCA.

Scrivener, J. (2005). Learning Teaching. London: Macmillan.

Swan, M. (1995). Practical English Usage (New edition). Oxford: Oxford University Press.

Thornbury, S. (1999). How to Teach Grammar. Harlow: Longman.

Willis, J. (1996). A flexible framework for task-based learning. In J. Willis, \& D. Willis (Eds.), Challenge and Change in Language Teaching (pp. 52-56). Oxford: Heinemann.

\section{Notes}

Note 1. For more information see 'A Framework for Task-Based Learning' by Jane Wills (1996); 'Doing Task-Based Teaching' by Dave and Jane Willis (2007). 


\section{Appendix (1)}

\section{Count and noncount nouns}

Common nouns can be divided into two types. Count (or countable) nouns refer to individual units you can count, such as books, eggs, and horses. Noncount (or mass) nouns refer to things or concepts which cannot be thought of as a collection of separate units, such as butter, music, and advice.

You can always tell the difference between a count and a noncount use of a noun by the grammar.

- Count nouns cannot stand alone in the singular, whereas noncount nouns can.

$$
\text { *Book is red. Music is fun. }
$$

So, book is a count noun, and music is a noncount noun.

- Count nouns allow a plural, whereas noncount nouns do not.

$$
\text { books eggs *musics *advices }
$$

- Count nouns occur in the singular with the word $a$, whereas noncount nouns take some. (Both types can occur with the.)
I'd like a book.
*I'd like a music.
*I'd like an advice.
*I'd like some book.
I'd like some music
I'd like some advice.
I like the book.
I like the music.
I like the advice.

Some nouns can be either count or noncount, depending on their meaning. Compare these sentences:

$$
\text { Have you bought a paper? Have you bought paper? }
$$

The first use is countable: it is a newspaper. The second use is uncountable: it is paper in general.

\section{Abstract and concrete nouns}

Both count and noncount nouns can be divided further into abstract and concrete types.

- Concrete nouns refer to things whose dimensions can be plotted and measured, such as book, referee, dog, butter, and windmill.

- Abstract nouns refer to general ideas or qualities, such as kindness, difficulty, condition, speed and truth.

It is often quite difficult to decide just how concrete or abstract a word is. Many nouns can be interpreted in either an abstract or a concrete way, depending on how they are being used. Music, for example, is concrete when you think of it as represented in a score, but it is abstract when you think of it as does Duke Orsino in Tmelfth Night: 'If music be the food of love ...'. Life is a fairly abstract notion in Isn't life monderful, but it becomes very concrete when it is weighed against cash in Your money or your life! 
Appendix 2

\author{
Activities \\ A $\mathbb{n}: \ldots<\cdot \ldots \ldots \cdot$. \\ Things which are countable: \\ mixing bowls \\ sieves \\ eggs \\ rolling pins \\ pastry cutters \\ balls \\ baking trays
}

GRAMMAR SHEET 24

Countable / Uncountable Recipe for Spiced Biscuits

Things which are uncountable:

flour

butter

brown sugar

salt

mixed spice

dough

icing sugar

\title{
' $a$ ' is missing. Add ' $a$ ' before the countable words:
}

Make sure you have all the ingredients before you start. For this recipe you need flour. ...... butter. ...... brown sugar, ...... small egg. ...... mixed spice. ..... salt and ...... icing sugar. First you should get all the cooking utensils you're going need, like ..... mixing bowl, ..... sieve. ...... pastry cutter and ..... rolling pin. You will need to beat the egg and measure the flour, the butter and the brown sugar before you start. Switch on the oven so that it can be getting hot: you should heat it to $190^{\circ} \mathrm{C} /$ Gas mark 5. Prepare ..... baking tray by greasing it with a little butter or oil.

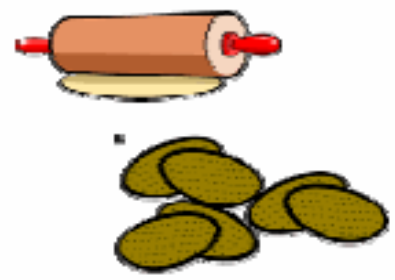

$$
\begin{gathered}
\text { Ingredients: } \\
250 \mathrm{~g} \text { plain flour } \\
125 \mathrm{~g} \text { butter } \\
125 \mathrm{~g} \text { brown sugar } \\
1 \text { small beaten egg } \\
2 \text { teaspoons mixed spice } \\
\text { a pinch of salt }
\end{gathered}
$$

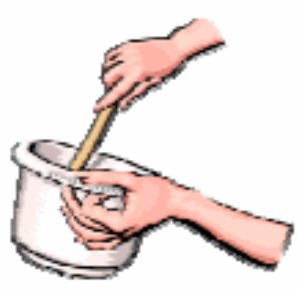

Method:

1. In ..... large mixing bowl, beat together the butter and the sugar until fluffy.

2. Beat in the egg little by little.

3. Sift in the flour, salt and spice, and mix everything together well.

4. Make it into ...... ball of dough.

5. Sprinkle some flour onto ..... clean work surface, and onto ..... rolling pin.

6. Roll out the dough until it is about $\frac{1}{2} \mathrm{~cm}$ thick.

7. Cut the dough into biscuit shapes, using ..... pastry cutter.

8. Use the odd pieces of dough which are left by making them into another ball.

9. Roll it out again and make more biscuits.

10. Put the biscuits on ..... greased baking tray and bake them in the oven for about 15 minutes.

11. Take them out when they are light brown, and put them on ..... wire rack to cool.

12. Decorate them with ..... icing sugar by sprinkling it through ..... sieve.

(Adapted from: eslteachersboard.com) 


\section{Copyrights}

Copyright for this article is retained by the author(s), with first publication rights granted to the journal.

This is an open-access article distributed under the terms and conditions of the Creative Commons Attribution license (http://creativecommons.org/licenses/by/4.0/). 